Juan Francisco Manzano. Autobiografía del esclavo poeta yotros escritos. Edición, introducción y notas de William Luis. Madrid/Frankfurt: Iberoamericana/ Vervuert, 2007.

\title{
EL COPISTA INVISIBLE
}

En el año 1835 el esclavo pardo Juan Francisco Manzano, cumpliendo la petición recibida del famoso abolicionista Domingo del Monte, completaba la redacción de su autobiografía, la única escrita por un esclavo en toda Latinoamérica. Desde aquel año, y hasta la publicación de la edición que aquí reseño, a cargo de William Luis, el texto de Manzano ha sufrido (y la elección del verbo no es casual) manipulaciones constantes en las que, a modo de introducción, vale la pena detenerse.

$\mathrm{Al}$ recibir el manuscrito, Del Monte entrega la primera mitad del mismo a Anselmo Suárez y Romero y la segunda a Ricardo de Palma, ambos integrantes de la tertulia delmontina, a los cuales pide que lo corrijan. Si bien de Palma extravió los documentos recibidos (que hasta hoy continúan perdidos), para 1839 Suárez y Romero había cumplidola misión encomendada. Fue su versión la que recibió Richard Madden, Superintendente de Libertos Africanos y miembro del Tribunal Mixto de Arbitraje de La Habana, el cual a su vez realizó una muy personal traducción incluida bajo el título "Life of the Negro Poet" en un volumen presentado a la Convención Internacional contra la esclavitud en Londres en 1840. Tomando también como punto de partida el manuscrito de Suárez y Romero, Francisco Calcagno incluyó varios fragmentos de la Autobiografía en su Poetas de color (1878) y Nicolás de Azcárate preparó una nueva copia en 1852. Por contra, José Luciano Franco partió del manuscrito original (que se conserva hoy en la Biblioteca Nacional José Martí de La Habana) para su versión de 1937 (reeditada con algunas modificaciones por Israel Moliner en 1972), la cual a su vez sirvió de base para la edición bilingüe de Ivan Schulman aparecida en 1975. Además de todas estas, existe una versión de Abdeslam Azougarh (2000), quien parte del manuscrito original, si bien consulta el manuscrito de Suárez y Romero.

La edición que reseño da a conocer la copia de Azcárate (hallada a mediados de los ochenta del siglo pasado en la Biblioteca Sterling de la Universidad de Yale e inédita hasta ahora), y además ofrece una meticulosa transcripción del manuscrito original, al cual no somete a proceso alguno de edición. Es ésta, a nuestro entender, la principal aportación del volumen reseñado, incluso mayor que el de dar a conocer la carpeta de Azcárate (aspecto éste al que sin embargo Luis concede mayor preeminencia) por cuanto implica romper con una obsoleta tradición que ocultaba planteamientos hoy insostenibles. 
En su iluminador artículo "Límites históricos y epistemológicos en los estudios subalternos”, José Rabasa analiza las anotaciones y tachaduras con que comentaristas españoles cubrieron el códice azteca Telleriano-Remensis, afirmando que estos añadidos no sólo resultan "estéticamente repugnantes”, sino que además “destruyen la integridad física y epistemológica del manuscrito” (108). En su estudio, Rabasa parte de los presupuestos teóricos de los estudios subalternos, que, en palabras de Gayatri Spivak, había llamado la atención sobre la imposibilidad de los sujetos subalternos de articular su propia voz, así como de la tendencia de tantos intelectuales y escritores a hablar por aquéllos. La tradición con la que rompe ahora Luis resultaba tan repugnante y destructora como la que menciona Rabasa, por cuanto partía de entender el texto original de Manzano como una pieza inacabada, a la disposición de cualquier letrado blanco que supiera otorgarle los significados que su autor se había mostrado incapaz de incorporar.

Desde Suárez y Romero hasta Schulman, y en menor medida Azougarh, los copistas se otorgaron a sí mismos el derecho de modificar en mayor medida las palabras de Manzano, borrando, añadiendo, corrigiendo la sintaxis, separando en párrafos, etc. en un proceso que supuestamente limpiaba el original y lo hacía más accesible. Como indicara al respecto Sylvia Molloy tal "noción (compartida por muchos), de que en la Autobiografía de Manzano hay una clara narrativa, por así decirlo, aprisionada, esperando a que alguien la haga legible, equivale a otra mutilación, agresiva, que le niega al texto la capacidad de ser leído por sí mismo”. (54) Dieciséis años después de aquel justificado lamento de Molloy, (los mismos que ha pasado Luis buscando casas editoriales interesadas por publicar su trabajo) nos encontramos finalmente frente a un crítico dispuesto a ejercer de copista invisible, a permitir que sea el lector, sin intermediario alguno, que se enfrente al texto y lo juzgue por sí mismo, sin manipulaciones, correcciones o limpiezas.

Así, mientras que la versión de Schulman, por poner un ejemplo, se abría con la frase "La Señora Doña Beatriz de Justiz, Marquesa Justiz de Santa Ana, esposa del Señor Don Juan Manzano, cada vez que iba a su famosa hacienda el Molino gustaba de tomar las más bonitas criollas entre diez y once años” (44), la excepcional transcripción (que no versión) de Luis reza como sigue: “La S ${ }^{\text {ra }}$. Da . Beatriz de Justiz Marqueza Justiz de Sta. Ana, esposa del Sor. $\mathrm{D}^{\mathrm{n}}$ Juan Manzano, tenia gusto [de]


criollas, cuando eran de dies a onse años” (299). Corchetes, llaves y negritas guían al lector a través de un texto al que en su introducción Luis invita a enfrentarse de maneras diversas, concediendo importancias distintas al texto original, los añadidos posteriores o las correcciones. Es ahora al lector, y no al crítico de turno, al que le cabe el placer de abordar la lectura e interpretación del texto. 
La transcripción ofrecida evita reiterar el error en que cayeran las versiones anteriores, textos higienizados en extremo que no reflejaban, como indica Luis en referencia concreta a la de Calcagno "las dificultades que encuentra el esclavo en el uso de la escritura, un medio de expresión que el sistema esclavista había negado tanto a Manzano como a otros poetas pardos con habilidad para escribir y componer" (35). En su lugar, Luis da la voz al esclavo Manzano, respetando su desvío de la norma gramatical académica, su cercanía a la tradición oral, y ofreciendo de tal modo una información contextual muchísimo más rica que la de cualquier versión anterior. Si, como queda dicho, la meta de los estudios subalternos es que la voz del subalterno sea audible, la edición de Luis -quien, sin embargo, no menciona en ningún momento esta corriente teórica- resulta un esfuerzo modélico.

Puesto que la transcripción se complementa con nada menos que 457 notas a pie de página (cotejando el texto con las que del mismo ofrecen Franco y Azougarh), sólo le queda al lector decidir cuántas de las herramientas que se ponen a su alcance quiere aprovechar.

Junto a esta transcripción del manuscrito original y del citado cuaderno de Nicolás Azcárate, el volumen ofrece la obra de teatro Záfira (de la cual llama la atención la nula atención que le presta Luis en su introducción, ha de suponerse que como reflejo del poco interés que en ella percibe), las poesías incluidas en la copia de Azcárate y siete cartas enviadas por Manzano a Domingo del Monte, todo ello aderezado con una ingente cantidad de notas a pie de página, la mayoría de ellas fruto del cotejo con versiones anteriores.

A pesar de lo extraordinario del trabajo, a la introducción inicial cabe hacer una objeción. En el apartado III de la misma, a fin de mostrar la alternancia de episodios positivos y negativos en la autobiografía, Luis se refiere a un episodio de la vida de Manzano en que éste se distancia de su padre (negro) y "establece un vínculo mayor con su ama blanca, (sustituta de la madre biológica)" (34). Centrado en la cuestión de la disposición cronológica de los diversos eventos, el editor descuida un aspecto importantísimo, al que no hace referencia aquí ni en otro lugar de su edición: ¿hasta qué punto puede inferirse de la autobiografía (e incluso de unas poesías que siguen el modelo canónico europeo) un intento por parte de su autor de mostrar lo que podríamos denominar blanqueamiento cultural? ¿Es posible percibir en estos textos la construcción de un modélico negro cubano completamente asimilado a la cultura hispana? ¿Qué relación guarda todo ello con el tan repetido miedo al negro y la necesidad de los delmontinos de mostrar que el fin de la esclavitud no conllevaba la africanización de Cuba? La relación de todo ello con la posible autocensura de Manzano son aspectos no tratados en la introducción y que no dejan de echarse en falta. 
Con todo, hay que agradecerle a William Luis no sólo su meticuloso quehacer filólogo, sino la persistencia en dar a conocer un texto y un estudio que en su primera versión llegó a galeradas en 1991, justo antes de que desapareciera la editorial en que se iba a publicar. La obra de Manzano bien lo merece.

La Trobe University

Carlos Uxo

GuilLERmo Siles. El microrrelato hispanoamericano. La formación de un género en el siglo XX. Buenos Aires: Corregidor, 2007.

Hacía falta un libro que reuniera los innumerables y divergentes vericuetos de la crítica, agreste como el microrrelato mismo. En tono muy general, pudiera decirse que el estudio del microrrelato se concentra en dos grupos: los que lo estudiaron más tempranamente y lo nominaron microrrelato, viéndolo como un género nuevo, y los que lo estudiaron a partir de 1990 que, siguiendo las tendencias del momento, lo denominaron minicuento. Y en esto no ha habido consenso. Los teóricos estructuralistas franceses citados por Siles pudieran ser de ayuda en este logro. Siles hace un estudio exhaustivo de las posibles influencias que guiaron al microrrelato a ser hoy lo que es. Sus investigaciones minuciosas cubren aun teorías que tienen alguna relación con su estructura y sentido (Jolles, Genette, Borges, Bajtin, Todorov, Mignolo, etc). Este es un libro algo difícil de leer de corrido, pero no puede imaginarse un futuro estudioso que se acerque al microrrelato sin hacer uso de las innumerables citas y referencias que este volumen contiene. Siles ha producido una recopilación monumental de sus posibles influencias, algo abrumadora pero inmensamente útil. Desde luego, el formato del microrrelato es muy atractivo para el lector de hoy. Toma muy poco tiempo leerlo, pues puede decir mucho en pocas palabras. Para explicarlo hace falta prescindir de su característica más superficial: la brevedad. Además, es muy dúctil en los nuevos medios de comunicación que la tecnología ha proporcionado.Y obliga al buen decir, a una voz cuidada.

Sin embargo, el trabajo crítico que primero utiliza el vocablo microrrelato, se menciona pero no se cita, a pesar de sus detalladas descripciones. La contribución a la crítica hispanoamericana que hizo el Instituto Internacional de Literatura Iberoamericana no debe ser pasada por alto tan ligeramente. Las memorias del Congreso que se celebró en 1981 en Austin, Texas, no se publicaron hasta 1986. Están precedidas de una disertación doctoral (CUNY) defendida en enero de 1986: "El micro-relato en México: Julio Torri, Juan José Arreola y Augusto Monterroso", aunque Siles confiesa que no la ha leído. El primer text académico que usó el 